\title{
Inactivation of MSH3 by promoter methylation correlates with primary tumor stage in nasopharyngeal carcinoma
}

\author{
HAIFENG NI, BO JIANG, ZHEN ZHOU, XIAOYANG YUAN, XIAOLIN CAO, GUANGWU HUANG and YONG LI
}

\author{
Department of Otolaryngology, Affiliated Hangzhou First People's Hospital of \\ Nanjing Medical University, Hangzhou, Zhejiang 310006, P.R. China
}

Received December 7, 2015; Accepted June 22, 2017

DOI: $10.3892 /$ ijmm.2017.3044

\begin{abstract}
The aim of this study was to investigate the inactivation of the MutS homolog human 3 (MSH3) gene by promoter methylation in nasopharyngeal carcinoma (NPC). Methylation-specific PCR, semi-quantitative reverse transcription PCR and immunohistochemical analysis were used to detect methylation and the mRNA and protein expression levels of MSH3 in 54 cases of NPC tissues and 16 cases of normal nasopharyngeal epithelial (NNE) tissues. The association between promoter methylation and mRNA expression, and the mRNA and protein expression of the gene and clinical factors was analyzed. The promoter methylation of MSH3 was detected in $50 \%(27 / 54)$ of the primary tumors, but not in the $16 \mathrm{NNE}$ tissues. The mRNA and protein expression levels were significantly decreased in the 54 cases of human NPC as compared to the $16 \mathrm{NNE}$ tissues $(\mathrm{P}<0.05)$. The MSH3-methylated cases exhibited significantly lower mRNA and protein expression levels than the unmethylated cases $(\mathrm{P}<0.05)$. The MSH3 mRNA and protein expression levels were significantly associated with the variable $\mathrm{T}$ stage $(\mathrm{P}<0.05)$; however, they did not correlate with the age and sex of the patients, or with the N stage, TNM classification or histopathological subtype $(\mathrm{P}>0.05)$. On the whole, MSH3 was frequently inactivated by promoter methylation and its mRNA and protein expression correlated with the primary tumor stage in NPC.
\end{abstract}

\section{Introduction}

Nasopharyngeal carcinoma (NPC) is one of the most common malignant tumors in South China, and its morbidity and mortality are ranked first globally. The etiology of NPC is multifactorial. Accumulated epidemiological and etiological evidence indicate that NPC develops from a complex interaction

Correspondence to: Dr Yong Li, Department of Otolaryngology, Affiliated Hangzhou First People's Hospital of Nanjing Medical University, 261 Huansha Road, Hangzhou, Zhejiang 310006, P.R. China E-mail: leeyung828@sina.com

Key words: MutS homolog human 3, nasopharyngeal carcinoma, promoter methylation, mRNA expression, protein expression between genetic factors, exposure to chemical carcinogens and latent Epstein-Barr virus (EBV) infection (1).

In recent years, studies have indicated that genetic changes in the classical oncogenes and tumor suppressor genes are rare in NPC, and the epigenetic changes in tumor suppressor genes, particlarly DNA methylation, play an important role in its development. NPC exhibits a high frequency of genetic $\mathrm{CpG}$ island methylation of the tumor. Moreover, tumor-associated gene methylation changes in NPC cells is involved in many functional processes, including cell cycle regulation, DNA repair, apoptosis, tumor invasion and metastasis (1-3). However, to date, and to the best of our knowledge, the epigenetic changes of the MutS homolog human 3 (MSH3) gene in NPC have not yet been investigated.

Mismatch repair genes maintain the stability of the genome by correction of base mismatch during DNA recombination and replication, and this eliminates the potential for carcinogenic changes by mutant cell growth via induction of cellular apoptosis. Thus, the mismatch repair of genes in the maintenance of genomic integrity, the repair of damage caused by cancer-specific factors and the anticancer process itself all play a very important role (4).

MSH3 is a member of the mismatch repair genes, which is located on chromosome 5q11-13. The MSH3 gene consists of 24 exons and 23 introns and is expressed in a variety of human tissues. MutS $\beta$ is a heterodimer of MSH2 and MSH3, and is primarily responsible for the repair of insertion-deletion loops (IDLs) of 1-15 nucleotides, as well as DNA loop and DNA double-strand breaks, which can trigger apoptosis of cells with high levels of DNA damage, and can also regulate the sensitivity of tumor cells to radiotherapy and chemotherapeutic drugs (5-10).

It has been suggested that human MSH3 (hMSH3) deficiency can drive hamartomatous polyposis syndrome tumorigenesis (11). MSH3 deficiency in human colonic epithelial cells results in elevated microsatellite instability at selected tetranucleotide repeats, and in the formation of DNA double-strand breaks, as well as significant proteomic changes, although it lacks oncogenic transformation (12). MSH3 knockout mice develop cancers only in later life (13); however, a double knockout of MSH3 and MSH6 renders mice far more susceptible to cancer than the single knockout of either gene (14). Therefore, MSH3 is considered a tumor suppressor gene. 
Previous studies have considered that gene mutation and homozygous deletion are the main mechanisms of tumor suppressor gene transcription inactivation. However, recent studies have confirmed that promoter methylation is the third mechanism of the tumor suppression of gene transcription inactivation, and in some cases the only mechanism of tumor suppressor gene inactivation (15). MSH3 protein expression has been shown to be downregulated in colorectal (16), gastric (17), bladder (18), prostate (19), ovarian (20) and other cancers, although each cancer type presents with its own inactivation mechanism. Mutations have rarely been found in MSH3 (21), and the loss of heterozygosity (LOH) and gene promoter GpG island methylation are the predominant modes of inactivation of MSH3 (16-18,22).

In this study, to screen novel epigenetic inactivation of tumor suppressor genes in NPC, we used a genome-wide screening of genes that were downregulated by promoter hypermethylation. In our previous study, the mRNA expression levels were frequently absent or downregulated in MSH3-methylated NPC primary tumor biopsies as compared to normal nasopharyngeal epithelial (NNE) tissues (unpublished data). However, MSH3-unmethylated cases exhibited upregulated or parallel mRNA expression levels. Thus, MSH3 may be a target gene with its expression suppressed by promoter hypermethylation in NPC.

In this study, we detected the methylation status, and the mRNA and protein expression levels in NPC primary tumor biopsies. We further analyzed the correlation between promoter methylation and mRNA expression. The above-mentioned evidence supports our hypothesis that MSH3 is epigenetically inactivated in NPC by promoter hypermethylation.

\section{Materials and methods}

Primary tumor biopsies and NNE tissues. A total of 54 NPC primary tumor biopsies was collected from the Department of Otolaryngology Head and Neck Surgery, Hangzhou First People's Hospital (Hangzhou, China), and 16 NNE tissues were obtained by tonsillectomy as normal controls, after obtaining written informed consent from the donors. Diagnoses were established by experienced pathologists according to the World Health Organization (WHO) classification. Biopsy samples were stored in liquid nitrogen prior to DNA or RNA extraction or paraffin sectioning. This study was approved by the local Ethics Committee of Hangzhou First People's Hospital, Hangzhou, China (approval ID: 201202501).

Semi-quantitative reverse transcription-PCR (RT-PCR). The preparation of total RNA, first-strand synthesis of $C D N A$ and RT-PCR was performed as previously described (23). All primer sequences, annealing temperatures, cycling conditions and expected PCR product sizes are listed in Table I. $\beta$-actin was amplified from the same cDNA sample as an internal control. The amplified PCR products were visualized following electrophoresis on $2 \%$ agarose gels and semi-quantitative analysis was performed using Quantity One v 4.4.0 software (Bio-Rad Laboratories, Inc, Hercules, CA, USA).

Immunohistochemical staining. The immunohistochemical staining procedure was carried out as previously described (24). Briefly, human tissue sections were stained for the expression of MSH3 [EPR4334(2); ab111107; 1:500] (Abcam, Cambridge, MA, USA) and detected by streptavidin-biotin-horseradish peroxidase complex formation. Tumor sections that were stained by isotype-matched immunoglobulin $\mathrm{G}$ instead of primary antibodies were used as a negative control.

The intensity of staining of the tissues was scored from 0-3 (i.e., absent, mild, moderate and intense) and the percentage of positive staining of cells was scored from 0-3 (i.e., 0, 0-5\%; $1,6-25 \% ; 2,26-50 \%$; and 3, 51-100\%) The MSH3 protein expression score was calculated by multiplying these two scores (i.e., as indicated by the codes:,$- 0 ;+, 1$ to $2 ;++, 3$ to 5 ; and ,+++ 6 to 9 ).

Sodium bisulphite modification of genomic DNA and methylation-specific PCR (MSP). The procedure for the sodium bisulfite modification of DNA was performed as previously described $(23,25)$. Bisulfite-modified DNA was amplified using MSP with primer sets that specifically detected methylated or unmethylated alleles. All primer sequences, annealing temperatures, cycling conditions and expected PCR product sizes are listed in Table II, PCR products were separated on $2 \%$ agarose gels.

Statistical analysis. The statistical software package SPSS 17.0 (SPSS, Inc., Chicago, IL, USA) was used in this study to biometrically assess the data. MSH3 expression levels in primary tumors versus NNE tumors and MSH3 methylated versus unmethylated tumors were analyzed by Mann-Whitney's $\mathrm{U}$ test. The correlations between MSH3 mRNA or protein expression levels and the clinicopathological characteristics were analyzed by the Student's t-test or the rank sum test. A P-value $<0.05$ was considered statistically significant.

\section{Results}

Primary tumors frequently lack MSH3 $\mathrm{mRNA}$ and protein expression. To evaluate the mRNA expression levels of MSH3 in primary NPC biopsies, semi-quantitative RT-PCR was carried out. MSH3 mRNA expression was detected in all NNE tissues (Fig. 1: N1, N2 and N3 used as samples); however, MSH3 expression was frequently absent or downregulated in the 54 NPC biopsy specimens (Fig. 1: T1, T2 and T3 used as samples). In addition, to evaluate the protein expression of MSH3 in the NNE tissues and NPC biopsy specimens, immunohistochemical staining was performed. MSH3 protein expression was detected in all NNE tissues (Fig. 2A and Table III), while MSH3 protein expression was frequently absent or downregulated in the 54 NPC biopsy specimens (Fig. 2B and Table III).

Hypermethylation of MSH3 in NPC primary tumors. To investigate the promoter methylation status of MSH3, MSP was performed. The promoter methylation of MSH3 was detected in 50\% (27/54) of the primary tumors (Fig. 4: T1, T2 and T3 used as samples); however, this was not found in any of the 16 cases of normal nasopharyngeal primary epithelial tissues (Fig. 3: N1, N2 and N3).

Inactivation of MSH3 correlates with its promoter hypermethylation. To verify whether the mRNA inactivation of MSH3 is related to promoter methylation in NPC, we detected the 
Table I. Primer sequence of MSH3 and $\beta$-actin genes for the semi-quantitative reverse transcription PCR (RT-PCR) assay.

\begin{tabular}{|c|c|c|c|}
\hline Primer & Primer sequence $5^{\prime} \rightarrow 3^{\prime}$ & Product size & Annealing temperature \\
\hline \multicolumn{4}{|c|}{ MSH3 primer } \\
\hline Sense & 5'-GATGGCATTTTCACAAGGATGGG-3' & $244 \mathrm{bp}$ & $57^{\circ} \mathrm{C}$ \\
\hline Antisense & 5'-CTGGCGGATAATGGGTGACAAAC-3' & & \\
\hline \multicolumn{4}{|c|}{$\beta$-actin primer } \\
\hline Sense & 5'-ACACTGTGCCCATCTACGAGG-3' & $621 \mathrm{bp}$ & $58^{\circ} \mathrm{C}$ \\
\hline Antisense & 5'-AGGGGCCGGACTCGTCATACT-3' & & \\
\hline
\end{tabular}

MSH3, MutS homolog human 3.

Table II. Primer sequence of MSH3 genes for the methylation-specific PCR.

\begin{tabular}{|c|c|c|c|}
\hline Primer & Sequence $5^{\prime} \rightarrow 3^{\prime}$ & Product size & Annealing temperature \\
\hline \multicolumn{4}{|c|}{ Methylated primer } \\
\hline Sense & 5'-GGAGGATTTTCGAGTTCGTTC-3' & 174 bp & $57.5^{\circ} \mathrm{C}$ \\
\hline Antisense & 5'-CGACCGCAATTCCCAAACG-3' & & \\
\hline \multicolumn{4}{|c|}{ Unmethylated primer } \\
\hline Sense & 5'-GGAGGATTTTTGAGTTTGTTT-3' & 175 bp & $55.5^{\circ} \mathrm{C}$ \\
\hline Antisense & 5'-ACAACCACAАТТССCAAACA-3' & & \\
\hline
\end{tabular}

MSH3, MutS homolog human 3.
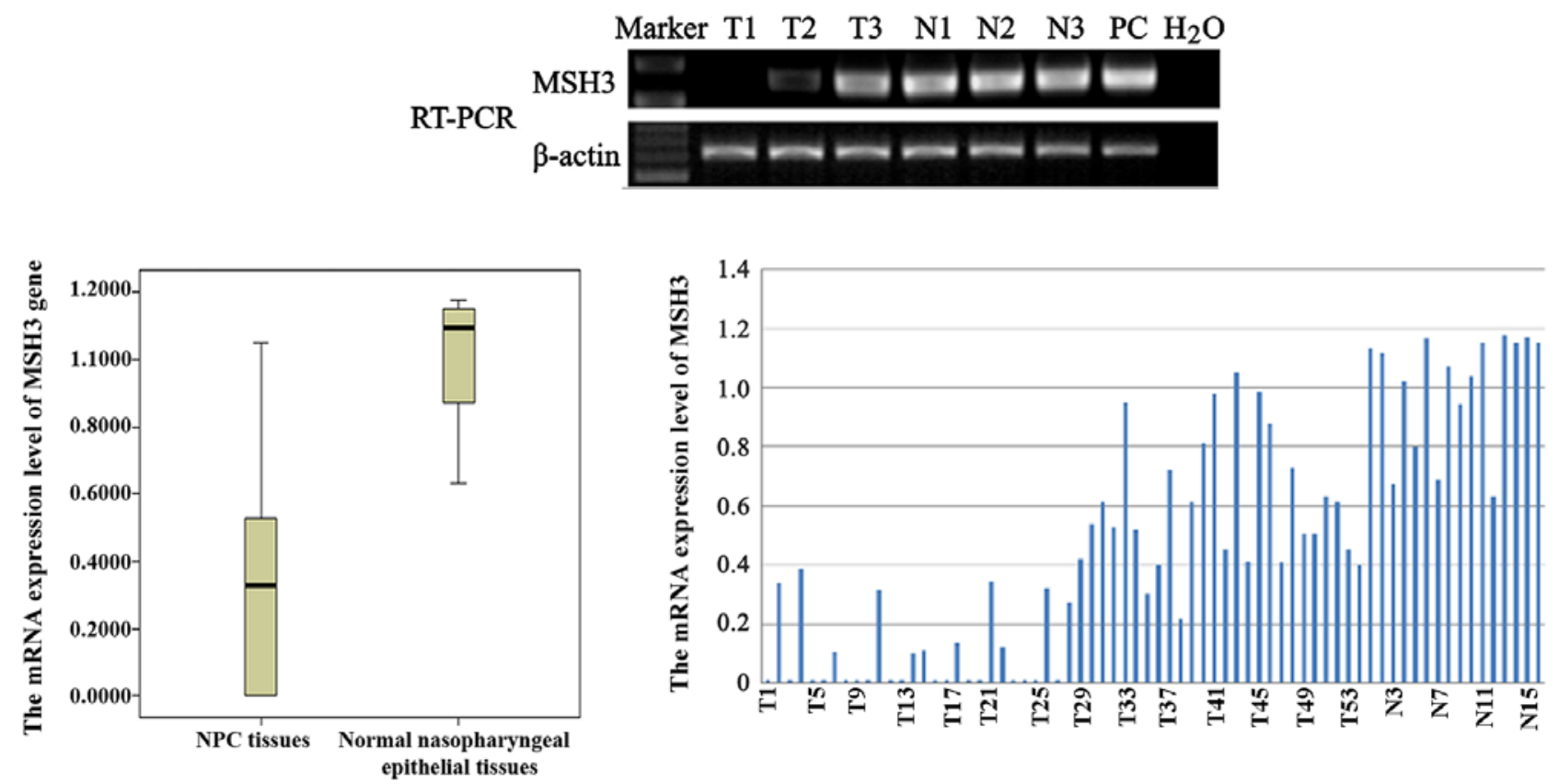

Figure 1. RT-PCR analysis of the mRNA expression of MutS homolog human 3 (MSH3), and the mRNA expression levels of MSH3 in nasopharyngeal carcinoma (NPC) biopsies (i.e., T1, T2, and T3) and normal nasopharyngeal epithelial (i.e., N1, N2, and N3) samples. The data are representative of 2 independent experiments. In addition, $\beta$-actin, normal colorectal tissue and water were used as an internal control, positive controls (PC) and blank control, respectively.

methylation status of the MSH3 gene by MSP. The promoter methylation of MSH3 was detected in 50\% (27/54) of primary tumors, among which 16 cases (i.e., T1,T5,T6,T8,T9, T10,T12,T13,T16,T17,T19,T20,T23,T24,T25,T27; Fig. 1) were
MSH3-silenced. Combined with the previous RT-PCR results, a decreased level of MSH3 expression was observed among the MSH3-methylated NPC cases as compared to the unmethylated cases $(\mathrm{P}<0.05$, Mann-Whitney's U test; Fig. 4). 
Table III. The protein expression levels of MSH3 in NNE tissues and NPC biopsies.

\begin{tabular}{lrrrccr}
\hline Biopsies & - & + & ++ & +++ & $\mathrm{z}$ & P-value \\
\hline NPC & 16 & 14 & 13 & 11 & 3.986 & 0.0003 \\
NNE & 0 & 0 & 3 & 13 & & \\
\hline
\end{tabular}

MSH3, MutS homolog human 3; NNE; normal nasopharyngeal epithelial; NPC nasopharyngeal carcinoma.

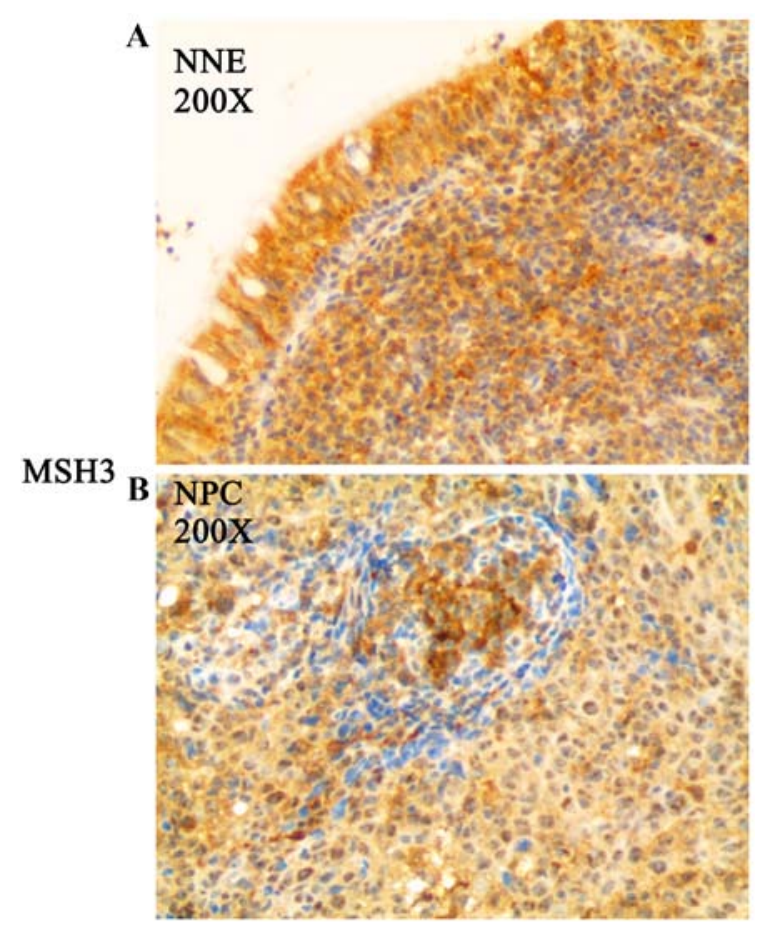

Figure 2. Immunohistochemical staining of the protein expression of MutS homolog human 3 (MSH3) in normal nasopharyngeal epithelial (NNE) tissues and primary nasopharyngeal carcinoma (NPC) biopsy specimens. (A and B) Represent examples of NNE and NPC, respectively.

MSP

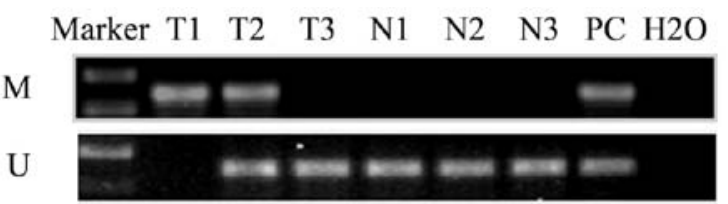

Figure 3. Methylation-specific PCR analysis of the MutS homolog human 3 (MSH3) promoter region in nasopharyngeal carcinoma biopsies (i.e., T1, T2, and T3) and normal nasopharyngeal primary epithelial (i.e., N1, N2, and N3) samples. The data are representative of 2 independent experiments. In vitro methylated DNA was used as a methylation-positive control and DNA from normal lymphocytes was used as an unmethylated positive control. Water was included as a blank control. M, methylated alleles; U, unmethylated alleles; PC, positive control.

Clinicopathological significance of MSH3 gene expression. We found that the MSH3 mRNA and protein expression levels were markedly associated with the variable $\mathrm{T}$ stage $(\mathrm{P}<0.05)$; however, this did not correlate with the age or sex of the patients, the stage, NM classification, or the histopathological subtype $(\mathrm{P}>0.05$; Tables IV and $\mathrm{V})$.

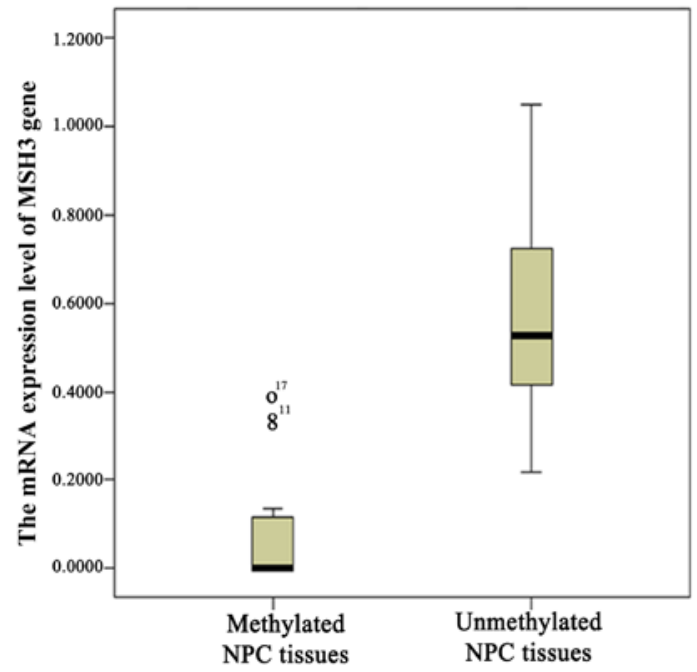

Figure 4. The mRNA expression level of MutS homolog human 3 (MSH3) in methylated nasopharyngeal carcinoma (NPC) tissues and unmethylated NPC tissues.

\section{Discussion}

Tumor cells frequently exhibit deficiencies in the signaling or repair of DNA damage. These deficiencies probably contribute to the pathogenesis of many diseases; however, a type of genetic stability is required, which can be obtained by overexpressing specific DNA repair genes, in order to produce primary tumor cells that are sufficiently genetically stable to be able to invade and give rise to distant metastases. They also present an opportunity to target the tumor. The dual roles of the DNA repair pathway in cancer highlights how an understanding of DNA repair processes can be used in the development of novel cancer treatments. Thus, the role and expression of the regulatory mechanism of the DNA mismatch repair gene, MSH3, in NPC is of particular importance and is largely unresolved.

In the present study, we demonstrated that the mRNA and protein expression levels of MSH3 in the NPC tissues were downregulated, which indicated that MSH3 played a major role as a tumor suppressor gene in the development of NPC. Our MSP results revealed that MSH3 promoter methylation was detected in $50 \%$ of the primary tumors, but was not detected in the NNE tumors. Therefore, MSH3 methylation was a frequent and tumor-specific process in NPC. The MSP and semi-quantitative RT-PCR data exhibited a correlation between the mRNA expression levels and the methylation status in NPC primary tumors. In this context, methylation inactivation appears to be a major mechanism in the loss of MSH3 expression. Thus, MSH3 gene methylation has a similar role in gastric cancer, bladder cancer and NPC, and yet plays differential roles in colorectal cancer, ovarian cancer and oral squamous cell carcinoma, in which $\mathrm{LOH}$ was the major regulatory mechanism for the inactivation of MSH3 gene expression $(16-18,22)$.

Vymetalkova et al found the significant overexpression of the MSH3 gene in colon tumors as compared to adjacent mucosal tissues (26). By contrast, it has been reported that the high frequency of $\mathrm{LOH}$, as well as aberrant protein expression, indicate an involvement of impaired MSH3 in the low level of microsatellite instability in colorectal cancer (16). Kawakami et al revealed that decreased hMSH3 protein expres- 
Table IV. Correlation between MSH3 mRNA expression and the clinical data of the patients with NPC.

\begin{tabular}{|c|c|c|c|}
\hline Clinical data & $\mathrm{n}$ (case) & mRNA expression & P-value \\
\hline Sex & & & $\mathrm{P}=0.935$ \\
\hline Male & 39 & $0.3346 \pm 0.2950$ & \\
\hline Female & 15 & $0.3426 \pm 0.3744$ & \\
\hline Age, years & & & $\mathrm{P}=0.890$ \\
\hline$<50$ & 33 & $0.3417 \pm 0.2918$ & \\
\hline$\geq 50$ & 21 & $0.3293 \pm 0.3566$ & \\
\hline Tumor size stage & & & $\mathrm{P}=0.033$ \\
\hline $\mathrm{T} 1 \mathrm{~T} 2$ & 35 & $0.4077 \pm 0.3462$ & \\
\hline T3T4 & 19 & $0.2164 \pm 0.2118$ & \\
\hline $\begin{array}{l}\text { Lymph node } \\
\text { metastasis }\end{array}$ & & & $P=0.636$ \\
\hline Absence & 18 & $0.3659 \pm 0.2968$ & \\
\hline Presence & 36 & $0.3223 \pm 0.3273$ & \\
\hline Tumor stage & & & $\mathrm{P}=0.505$ \\
\hline III & 19 & $0.3761 \pm 0.3153$ & \\
\hline IIIIV & 35 & $0.3155 \pm 0.3178$ & \\
\hline Histological subtypes & & & $\mathrm{P}=0.724$ \\
\hline $\begin{array}{l}\text { Non-keratinizing } \\
\text { carcinoma }\end{array}$ & 48 & $0.3156 \pm 0.4024$ & \\
\hline $\begin{array}{l}\text { Keratinizing } \\
\text { squamous cell } \\
\text { carcinoma }\end{array}$ & 6 & $0.3342 \pm 0.3563$ & \\
\hline
\end{tabular}

Staging is according to the International Union against Cancer (UICC). MSH3, MutS homolog human 3; NPC nasopharyngeal carcinoma.

sion levels in bladder cancer may play a significant role in the progression of bladder tumors. An inverse correlation between hMSH3 protein expression levels with the pathological grade was also found (18). However, in the present study, we demonstrated that MSH3 mRNA and protein expression levels in the NPC tissues were significantly and inversely associated with the variable $\mathrm{T}$ stage. This observation suggested that MSH3 mRNA and protein expression could be considered an indicator of local invasion by the primary tumor. Thus, the role of MSH3 as a tumor suppressor gene in NPC is similar to that of colorectal and bladder cancer, although the specific mechanisms of functional gene expression of MSH3 in different cancers vary considerably.

Conde et al discovered that the variant in MSH3, referred to as Ala1045Thr, was associated with a decreased risk of breast cancer (27). The results presented in the studies by Jafary et al and Hirata et al demonstrated that MSH3 codon 222 and MSH3 codon 1036 polymorphisms may represent an increased risk factor for sporadic prostate cancer $(28,29)$. Michiels et al reported that MSH3 single-nucleotide polymorphisms may be associated with an increased risk of lung cancer (30). Koessler et al reported a single nucleotide polymorphism of rs863221, located in MSH3 that was associated with diseasespecific survival in patients with colorectal cancer (31). Dong et al discovered that MSH3 single-nucleotide polymorphisms correlated with overall survival in patients with
Table V. Correlation between MSH3 protein expression and the clinical data of the patients with NPC.

\begin{tabular}{|c|c|c|c|c|c|c|}
\hline Clinical data & $\mathrm{n}$ (case) & - & + & ++ & +++ & P-value \\
\hline Sex & & & & & & $\mathrm{P}=0.928$ \\
\hline Male & 39 & 10 & 12 & 11 & 6 & \\
\hline Female & 15 & 6 & 2 & 2 & 5 & \\
\hline Age, years & & & & & & $\mathrm{P}=0.509$ \\
\hline$<50$ & 33 & 8 & 9 & 10 & 6 & \\
\hline$\geq 50$ & 21 & 8 & 5 & 3 & 5 & \\
\hline Tumor size stage & & & & & & $\mathrm{P}=0.047$ \\
\hline $\mathrm{T} 1 \mathrm{~T} 2$ & 35 & 7 & 11 & 6 & 11 & \\
\hline T3T4 & 19 & 9 & 3 & 7 & 0 & \\
\hline $\begin{array}{l}\text { Lymph node } \\
\text { metastasis }\end{array}$ & & & & & & $\mathrm{P}=0.292$ \\
\hline Absence & 18 & 2 & 7 & 6 & 3 & \\
\hline Presence & 36 & 14 & 7 & 7 & 8 & \\
\hline Tumor stage & & & & & & $\mathrm{P}=0.245$ \\
\hline III & 19 & 2 & 9 & 3 & 5 & \\
\hline IIIIV & 35 & 14 & 5 & 10 & 6 & \\
\hline Histological subtypes & & & & & & $\mathrm{P}=0.424$ \\
\hline $\begin{array}{l}\text { Non-keratinizing } \\
\text { carcinoma }\end{array}$ & 48 & 24 & 1 & 15 & 8 & \\
\hline $\begin{array}{l}\text { Keratinizing } \\
\text { squamous cell } \\
\text { carcinoma }\end{array}$ & 6 & 3 & 0 & 2 & 1 & \\
\hline
\end{tabular}

Staging is according to the International Union against Cancer (UICC). MSH3, MutS homolog human 3; NPC nasopharyngeal carcinoma.

pancreatic cancer (32). However, the majority of the cases were followed-up for $>5$ years, and thus the 5 -year survival rate of the patients was not analyzed. In the future, the role of MSH3 in the pathogenesis, prognosis and risk estimation of NPC needs to be further clarified after the relevant follow-up data of the past 5 years is analyzed statistically.

Previous evidence has suggested that MSH3-deficient as compared to proficient colorectal cancer cells exhibit an increased sensitivity to the irinotecan metabolite, SN-38, and to oxaliplatin, but not to 5-FU (9). Another study reported an attempt to identify an association between MSH2 and MSH3 genetic variants and development of radiosensitivity in breast cancer patients (10). Thus, the sensitivity of nasopharyngeal cancer patients to radiotherapy and chemotherapy is related to MSH3, which need to be confirmed by further experiments.

In addition, methylation-mediated inactivation is potentially a reversible phenomenon (33). As the MSH3 gene product has an anticancer effect, turning this process around and upregulating MSH3 by using demethylating agent treatment may probably prevent or reverse the malignant phenotype, and might therefore translate into a novel demethylating agent and therapeutic target in NPC.

In this study, it is a pity that we have only used tissue samples and have not performed any in vitro experiments on cell lines. We aim to further analyze the mRNA expression of the MSH3 
gene in NPC cell lines before and after treatment with the methyltransferase inhibitor, 5-aza-2-deoxycytidine, in future studies. We aim to provide evidence to further verify that $\mathrm{MSH} 3$ is epigenetically inactivated in NPC by promoter hypermethylation. The present study revealed that MSH3 is frequently inactivated by its promoter methylation and its mRNA and protein expression correlate with the primary tumor stage in NPC, suggesting that MSH3 mRNA and protein expression can be considered as such, an indicator of primary tumor local invasion, and would have a potential value in clinical applications. MSH3 may probably translate to a novel demethylating agent and therapeutic target in NPC. Whether the MSH3 gene can be used as a predictive indicator of the sensitivity of patients with NPC to radiotherapy and chemotherapy should be confirmed by further experiments.

\section{Acknowledgements}

This study was supported by grants from the Medical and Health Backbone Platform Foundation Project of Zhejiang Province, China (grant no. 2012RCB038).

\section{References}

1. Tao Q and Chan AT: Nasopharyngeal carcinoma: molecular pathogenesis and therapeutic developments. Expert Rev Mol Med 9: 1-24, 2007.

2. Lung HL, Cheung AK, Ko JM, Cheng Y, Stanbridge EJ and Lung ML: Deciphering the molecular genetic basis of NPC through functional approaches. Semin Cancer Biol 22: 87-95, 2012.

3. Lo KW, Chung GT and To KF: Deciphering the molecular genetic basis of NPC through molecular, cytogenetic, and epigenetic approaches. Semin Cancer Biol 22: 79-86, 2012.

4. Fishel R: The selection for mismatch repair defects in hereditary nonpolyposis colorectal cancer: revising the mutator hypothesis. Cancer Res 61: 7369-7374, 2001.

5. Jensen LE, Jauert PA and Kirkpatrick DT: The large loop repair and mismatch repair pathways of Saccharomyces cerevisiae act on distinct substrates during meiosis. Genetics 170: 1033-1043, 2005.

6. Gupta S, Gellert M and Yang W: Mechanism of mismatch recognition revealed by human MutS $\beta$ bound to unpaired DNA loops. Nat Struct Mol Biol 19: 72-78, 2011.

7. van Oers JM, Edwards Y, Chahwan R, Zhang W, Smith C, Pechuan X, Schaetzlein S, Jin B, Wang Y, Bergman A, et al: The MutS $\beta$ complex is a modulator of p53-driven tumorigenesis through its functions in both DNA double-strand break repair and mismatch repair. Oncogene 33: 3939-3946, 2014.

8. Owen BA, H Lang W and McMurray CT: The nucleotide binding dynamics of human MSH2-MSH3 are lesion dependent. Nat Struct Mol Biol 16: 550-557, 2009.

9. Park JM, Huang S, Tougeron D and Sinicrope FA: MSH3 mismatch repair protein regulates sensitivity to cytotoxic drugs and a histone deacetylase inhibitor in human colon carcinoma cells. PLoS One 8: e65369, 2013.

10. Mangoni M, Bisanzi S, Carozzi F, Sani C, Biti G, Livi L, Barletta E, Costantini AS and Gorini G: Association between genetic polymorphisms in the XRCC1, XRCC3, XPD, GSTM1, GSTT1, MSH2, MLH1, MSH3, and MGMT genes and radiosensitivity in breast cancer patients. Int J Radiat Oncol Biol Phys 81: 52-58, 2011.

11. Huang SC, Lee JK, Smith EJ, Doctolero RT, Tajima A, Beck SE, Weidner N and Carethers JM: Evidence for an hMSH3 defect in familial hamartomatous polyps. Cancer 117: 492-500, 2011.

12. Campregher C, Schmid G, Ferk F, Knasmüller S, Khare V, Kortüm B, Dammann K, Lang M, Scharl T, Spittler A, et al: MSH3-deficiency initiates EMAST without oncogenic transformation of human colon epithelial cells. PLoS One 7: e50541, 2012.

13. de Wind N, Dekker M, Claij N, Jansen L, van Klink Y, Radman M, Riggins G, van der Valk M, van't Wout K and te Riele H: HNPCC-like cancer predisposition in mice through simultaneous loss of Msh3 and Msh6 mismatch-repair protein functions. Nat Genet 23: 359-362, 1999.
14. Edelmann W, Umar A, Yang K, Heyer J, Kucherlapati M, Lia M, Kneitz B, Avdievich E, Fan K, Wong E, et al: The DNA mismatch repair genes Msh3 and Msh6 cooperate in intestinal tumor suppression. Cancer Res 60: 803-807, 2000.

15. Jones PA and Laird PW: Cancer epigenetics comes of age. Nat Genet 21: 163-167, 1999.

16. Plaschke J, Preußler M, Ziegler A and Schackert HK: Aberrant protein expression and frequent allelic loss of MSH3 in colorectal cancer with low-level microsatellite instability. Int J Colorectal Dis 27: 911-919, 2012.

17. Kim HG, Lee S, Kim DY, Ryu SY, Joo JK, Kim JC, Lee KH and Lee JH: Aberrant methylation of DNA mismatch repair genes in elderly patients with sporadic gastric carcinoma: a comparison with younger patients. J Surg Oncol 101: 28-35, 2010.

18. Kawakami T, Shiina H, Igawa M, Deguchi M, Nakajima K, Ogishima T, Tokizane T, Urakami S, Enokida H, Miura K, et al: Inactivation of the hMSH3 mismatch repair gene in bladder cancer. Biochem Biophys Res Commun 325: 934-942, 2004.

19. Sun X, Chen C, Vessella RL and Dong JT: Microsatellite instability and mismatch repair target gene mutations in cell lines and xenografts of prostate cancer. Prostate 66: 660-666, 2006.

20. Xiao X, Melton DW and Gourley C: Mismatch repair deficiency in ovarian cancer - molecular characteristics and clinical implications. Gynecol Oncol 132: 506-512, 2014

21. Heinen CD: Genotype to phenotype: analyzing the effects of inherited mutations in colorectal cancer families. Mutat Res 693: 32-45, 2010.

22. Nunn J, Nagini S, Risk JM, Prime W, Maloney P, Liloglou T, Jones AS, Rogers SR, Gosney JR, Woolgar J and Field JK: Allelic imbalance at the DNA mismatch repair loci, hMSH2, hMLH1, hPMS1, hPMS2 and hMSH3, in squamous cell carcinoma of the head and neck. Oral Oncol 39: 115-129, 2003.

23. Zhang Z, Sun D, Van N, Tang A, Hu L and Huang G: Inactivation of RASSF2A by promoter methylation correlates with lymph node metastasis in nasopharyngeal carcinoma. Int J Cancer 120: 32-38, 2007.

24. Huang XM, Dai CB, Mou ZL, Wang LJ, Wen WP, Lin SG, $\mathrm{Xu} \mathrm{G}$ and Li HB: Overproduction of cyclin D1 is dependent on activated mTORC1 signal in nasopharyngeal carcinoma: implication for therapy. Cancer Lett 279: 47-56, 2009.

25. Olek A, Oswald J and Walter J: A modified and improved method for bisulphite based cytosine methylation analysis. Nucleic Acids Res 24: 5064-5066, 1996.

26. Vymetalkova VP, Slyskova J, Korenkova V, Bielik L, Langerova L, Prochazka P, Rejhova A, Schwarzova L, Pardini B, Naccarati A and Vodicka P: Molecular characteristics of mismatch repair genes in sporadic colorectal tumors in Czech patients. BMC Med Genet 15: 17, 2014.

27. Conde J, Silva SN, Azevedo AP, Teixeira V, Pina JE, Rueff J and Gaspar JF: Association of common variants in mismatch repair genes and breast cancer susceptibility: a multigene study. BMC Cancer 9: 344, 2009.

28. Jafary F, Salehi M, Sedghi M, Nouri N, Jafary F, Sadeghi F, Motamedi S and Talebi M: Association between mismatch repair gene MSH3 codons 1036 and 222 polymorphisms and sporadic prostate cancer in the Iranian population. Asian Pac J Cancer Prev 13: 6055-6057, 2012.

29. Hirata H, Hinoda Y, Kawamoto K, Kikuno N, Suehiro Y, Okayama N, Tanaka Y and Dahiya R: Mismatch repair gene MSH3 polymorphism is associated with the risk of sporadic prostate cancer. J Urol 179: 2020-2024, 2008.

30. Michiels S, Danoy P, Dessen P, Bera A, Boulet T, Bouchardy C, Lathrop M, Sarasin A and Benhamou S: Polymorphism discovery in 62 DNA repair genes and haplotype associations with risks for lung and head and neck cancers. Carcinogenesis 28: 1731-1739, 2007.

31. Koessler T, Azzato EM, Perkins B, Macinnis RJ, Greenberg D, Easton DF and Pharoah PD: Common germline variation in mismatch repair genes and survival after a diagnosis of colorectal cancer. Int J Cancer 124: 1887-1891, 2009.

32. Dong X, Li Y, Hess KR, Abbruzzese JL and Li D: DNA mismatch repair gene polymorphisms affect survival in pancreatic cancer. Oncologist 16: 61-70, 2011.

33. Verma M, Maruvada P and Srivastava S: Epigenetics and cancer. Crit Rev Clin Lab Sci 41: 585-607, 2004. 